\title{
Research on the Strategy-based Instruction of News Broadcast Listening for English Minors in China
}

\author{
Jinzhu Zhang \\ School of Foreign Languages, Tianjin Polytechnic University, Tianjin, China
}

\begin{abstract}
News broadcast, as a kind of authentic input, are invaluable materials to improve listening proficiency for both ESL and EFL learners. However, the particular characteristics of news broadcast present a number of challenges to achieving comprehension: unfamiliar patterns of discourse, vocabulary, speech rates, syntactic structures, and a high density of factual contents, etc. in this paper, based on the Constructivism views on education, the author chooses 86 English learners in China who take English as their second major as the research subjects, carries out a strategy-based instruction to the experimental group. After the 15-week instruction, the author collects and analyses the data to examine whether the strategy-based instruction would help students improve their news listening performance.
\end{abstract}

Index Terms - constructivism, news broadcast listening, authentic input, strategies, strategy-based instructions

\section{INTRODUCTION}

In recent years, due to the increasing demands for quality education and the deepening of foreign language research in China, great changes have taken place in language education. As for the practice of English learning and instruction at college level, greater emphasis has been given to the training of skills of language use in the real world. Correspondingly, the aim of English education at college level has also transformed from the pure language input and acquisition to the development of learning and skills of application that will facilitate students to acquire knowledge automatically and use their language skillfully.

Among the four skills of foreign language learning, listening skill is considered to be a fundamental component of human communication behavior and has taken an even greater role. For many learners of English, the ability to understand news broadcast is perhaps the top criteria and object of second language or foreign language listening comprehension. In almost all universities and colleges in China, News Broadcast Listening has been a core course in the curriculum of English majors as well as a selective language course for intermediate-level English minors.

Many instructors in China (Yang, 2000; Dun, 2002; Xia, 2002; Cui, 2006; Han \& Zhou, 2006; Wang, 2011; Cheng, 2009; Chen, 2014) have been exploring effective methods in teaching News Broadcast listening based on various theoretical frameworks, but the plausibility and efficiency of their research for most listeners still need to be seen. The particular characteristics of news broadcast present a number of challenges to achieving comprehension.

In the teaching of News Broadcast listening, the author finds that most students recognize the value of news broadcast for their improvements of listening skills. But they are always discouraged by their slow improvements in understanding news broadcast. Of course, the proficiency of listening performance is decided by various elements, such as their motivation to listen, their scopes of knowledge, and their performance of other language skills, etc. But a clear and effective instruction and guidance from teachers can really give them the encouragement and stimulus to work harder to further their skills in news English listening.

Therefore, by using several research instruments, and with a sound Constructivism views on education in mind, the author aims to explore an effective way to help students understand news broadcast and ultimately develop students' independent thinking.

The major research question explored in the study will be: Will the strategy-based instruction on news listening facilitate their listening comprehension performance?

\section{LITERATURE REVIEW}

News broadcast listening is an important course for English majors to improve their listening comprehension skills in the authentic settings. The course aims not just to practice students' listening skills but also to broaden their horizons and develop their critical thinking abilities.

\section{A. Teaching of News Broadcast Listening in China}

News broadcast, as a kind of authentic input, are invaluable materials to improve listening proficiency for both ESL and EFL learners. In China, the opportunities for most ordinary English learners to have a face-to-face communication 
with the native speakers are really scarce. English News broadcast offers learners the real contexts language and abundant cultural knowledge, creating opportunities for learners to broaden their horizons as well as learn the foreign language.

Firstly, English news broadcast is a preferred and important means for students at various levels to learn English for different skills and develop their critical thinking abilities by broadening their horizons (Xia, 2002). English news plays an important part in cultural exchange, with a wide range of covering from the history of countries around the world, the hot issues of international community, the global politics and economy, to life and fashion of certain communities and the traditions of local places in every corner around. English in news is authentic, up-to-date and living language with abundant contents to be explored. What else, the pronunciation with various accents in the news broadcast around the world can help students deal with the situations where standard and naturally pronounced English are not always uttered. Its brief and concise writing styles with the typical characteristics of English language can help students to better understand and apply the writing approaches in their English writing.

Secondly, the syllabus for English or English minors all explicitly lay down the requirements for English news listening. The college English curriculum requirements released by the Department of Higher Education of National Ministry of Education has clearly stated that the listening ability of college English are set at three different levels: basic, intermediate and higher requirements. And the criterion chosen to make these distinctions of levels is the news broadcast from VOA with the special and standard edition. As for English majors, a distinctive and comparatively higher requirement of understanding VOA standard, BBC and CNN has been clearly specified in the latest version of syllabus of TEM-4 and TEM-8. However, the fact is that a majority of the tertiary English learners fail to meet the requirement, even the excellent English achievers.

Thirdly, a constant and persevering practice does not necessarily guarantee students' improvement in understanding the English news. Researchers have carried out the investigation among English majors. And the survey shows that nearly $80 \%$ of the subjects keep practicing and listening to English news programs (Han \& Zhou, 2006). Nevertheless, they could not achieve a distinct and satisfying progress in news listening.

Finally, as a course with a relatively short history, many problems still need to be solved and studied in the teaching and learning practice, which definitely has caused difficulties for many teachers.

\section{B. Challenges of News Broadcast Listening}

For many learners of English, the ability to understand news broadcast is perhaps the reflection of their foreign language proficiency. However, the particular characteristics of news broadcast present a number of challenges to achieving comprehension: unfamiliar patterns of discourse, vocabulary, speech rates, syntactic structures, and a high density of factual contents (Xia, 2004; Han, 2012). Furthermore, problems may arise due to insufficient background knowledge, familiar vocabulary that becomes unfamiliar in connected speech or is not expected in the given context, no opportunity to negotiate meaning and unfamiliar contexts and culture, etc. More specifically:

The first challenging obstacle is the insufficient background knowledge for the learners of news broadcast. The saying that "to know something about everything" has always been the requirement for all English majors. But most students get quite puzzled when listening to some reports about the current international affairs. Obviously, the lack of background knowledge has posed a great challenge for their listening comprehension. Some researchers (Teng, 2003; Cross, 2009; Han \& Zhou, 2006) have already illustrated that the background knowledge and familiar topics of the materials could greatly facilitate students' understanding of the news broadcast.

For most listeners of news broadcast listening, the second obstacle is the unfamiliar patterns of discourse. There are some highly regulated discourse patterns in the news broadcast. These patterns of discourse which originally could have served as the assistance of understanding news broadcast turns out to be one of the obstacles in understanding. This may result in the different thinking patterns and expression ways between the east and west.

The third important challenge for learners is the vocabulary or terminology. A good command of vocabulary in news listening is very important for news listening comprehension. Generally speaking, the news broadcast has a very wide range of coverage, from politics, economics, to military and cultural reports, etc. Therefore, the terminology employed in the news broadcast will be abundant and less commonly used compared with the other learning materials.

Fourthly, the rate of the speech is another difficult point in news listening comprehension. Most beginners of news listening tend to use the VOA special English, which is broadcast with the speed of 90 words per minute. But it is greatly agreed that a greater improvement in news listening can be made only when learners with intermediate levels practice with the news broadcast with the speed of 150 words per minute (Dun, 2002).

The last but not the least great challenge is that a piece of news report tries to convey the information to listeners within limited time, there is also a high density of factual content besides its speed in report. For many English learners, it is a great challenge to catch what they want to hear among a large amount of information in such a short time.

Above all, there may be different challenges for each individual besides the challenges referred above. If properly dealt with, challenges can become the opportunities for learners to make greater progress in listening proficiency. Therefore, it is teacher's task to help students seek out the challenges and solve them with the proper instruction in classroom teaching. 
In this part, the author would like to introduce the instruction model based on the conception of Constructivism. Then, the author would propose the design of the research on the strategy-based instruction in the classroom of News Broadcast Listening which has lasted for 15 weeks. After that, the author would collect the data and analyse them. Finally a conclusion was drawn.

\section{A. The Model of Constructivism Strategy-based Instruction}

Constructivism views on education believe that learning process is the harmonious combination of four elements, which are the learner, teacher, task, and the context where learning takes place. They exist as a dynamic and balanced model, which moves forward smoothly with the conception that education aims to empower learners to think independently and to perpetuate in the next generation ways of acting and thinking that are judged the best by present generation (Von Glazerfield, qtd.from Williams \& Burden 2000). Therefore, based on the Constructivism views on education (Williams \& Burden, 2000), a dynamic Constructivism strategy-based instruction is shown in table 1 below.

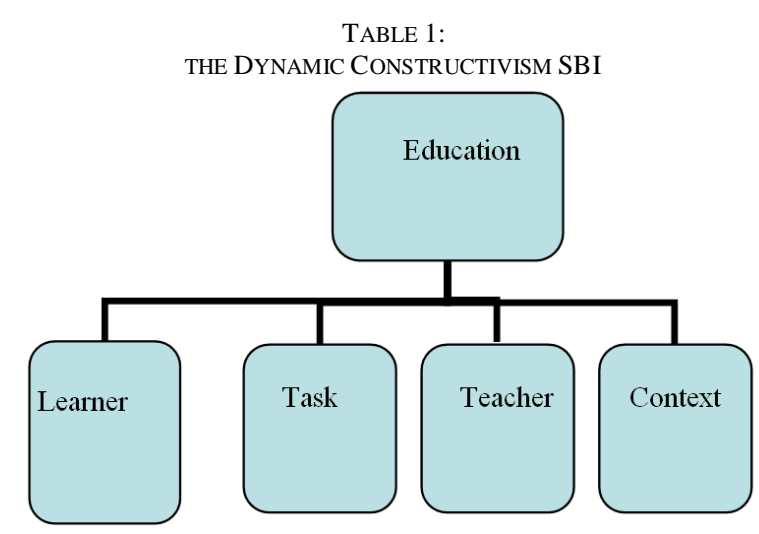

In this dynamic circle, Learner is considered as an independent person and thinker, an experiencer of learning and cultural difference, and an active participant in the learning process and class activities. Teacher in this model is taking his or her role as an assessor; planner; decision-maker; supporter of students' learning and a model of showing how to use the strategies. Tasks in this Constructivism model are the real-life English authentic news broadcast and the strategies instructed to facilitate students' autonomous learning and develop independent and critical thinking. The contexts where the learning and the strategy training take place should be harmonious and cooperative, where the teacher shows friendly and understanding behaviors, because the ultimate goal of education is to empower learners to think independently and develop autonomous learning.

\section{B. Research Design}

An experimental design was chosen since one of the goals of the research was to assess the effect of instruction in listening strategies. The present research, which aimed at training students to use some strategies, was designed firstly to investigate whether a significant difference in strategy use existed individually. And then whether improvements of news comprehension could be made through including the strategy training into the normal news broadcast teaching practice.

\section{Subjects}

Eighty-eight English minors at TJPU were selected as the subjects for the study. Most of them had got the scores above 425 points in CET Band- 4 or Band- 6.

They are the students taking English as their second major. They were also enrolled through a scientific and systematic written and oral examination. These English minors are from the majors of International Trade, Economics, Financing Management, Accounting, Journalism, Software Engineering, Telecommunications, Compound Materials and other science and engineering.

They are also highly motivated in studying English. Because it is a big and serious decision that they have to make before taking the English as their minors during the weekends for totally 3 years. Many of them have their future professional and academic goals through learning English and achieving a relatively higher degree of communicative competence. To some extent, the conception that English serving as a tool of future career tends to be more realistic than that of English majors.

The subjects involved in the research were divided into experimental group (EG) and the control group (CG). Class one was randomly chosen as the EG. Class two was randomly set as the CG. There were 43 students in EG and 45 students in CG. Then a before-test was carried out to see whether the students in both groups had a relatively same level of listening proficiency.

\section{Instruments}

The instruments of the research consist of a before-test and a post-test, interviews and a before-questionnaire and a post-questionnaire. 
Prior to the research, a researcher-designed audio-based test, which was adapted from the standardized tests of CET4 (Internet-based) and TEM-4, was used to measure students listening comprehension proficiency.

The CET-4 (Internet-based), which relies on the person-to-computer dialogue, is a reform presently being conducted on College English teaching and testing. From the year of 2008, it has been in a pilot stage in some key universities around China. A dramatic change of the exam is the inclusion of news brief listening, which makes the exam more challenging. And its validity and reliability on testing has been confirmed by researchers and teachers. TEM-4 (Test of English Majors) is another standardized examination for English majors nationwide, which has been held for about 20 years. Now it is one of two national examinations in which news listening broadcast is tested (another one is TEM-8). All the news broadcast and interviews which were used in the test were carefully chosen to include topics where background knowledge was modified to a degree that will not cause the partiality in comprehension. And the tests were composed of a series of clips ranging from 15 seconds (news briefings) to 3 minutes (interviews and features).

Another instrument used in the research was the interview. At the beginning of the research, the author randomly chose 5 students in each class for personal interviews. The 30-minute interviews were carried out in Chinese in order to enhance the efficiency of the interviews.

The questions for before-interview were as follows:

1. How do you think about your present listening proficiency?

2. Do you think news listening is difficult? If so, what are the difficult points?

3. Have you ever received listening strategy training before?

4. Do you think it is necessary to receive listening strategy training?

5 . What kind of listening strategies do you know?

The textbook edited by Guo Qingzhu in 2010 was also used in the research. The textbook chosen for the intensive listening course is the English Broadcast Listening (Elementary). A very important reason for the choice of this book as the course book is its timeliness in its topics, which attract students' interest and offer background knowledge for the students. The whole book covers 18 topics, ranging from the natural disasters, political chaos to presidential elections and regional conflicts, etc. The news items are all carefully selected concerning length, difficulties, and topics. The exercises are compiled in the forms of true or false questions, blank-filling, multiple choices and questions and answers, discussion.

Meanwhile, the author used the latest news broadcast of VOA special English or BBC Learning English and CRI English programs as the materials for extensive listening. BBC Learning English is a special English learning program for EFL or ESL learners from BBC, which is slower in speed and rich in contents. CRI English program is an English news program aiming for English learners and English natives in China, whose main concern is the news events in China. So it is easier for students to understand. They were required to retell the news briefly. Finally the author evaluated students' performance and supplemented the main points.

\section{Course Design}

At the beginning of the research, all subjects were informed that the purpose of the research was to improve listening comprehension of news broadcast. All subjects attended one of the two 15-week news listening courses for 2 hours each week.

Each lesson was composed of extensive listening and intensive listening. The extensive listening materials were downloaded from the BBC and VOA news websites and the intensive listening materials were from the textbook of English Broadcast Listening, which covers various topics.

The subjects in CG completed a 90-minute listening task with the same news broadcast, which similarly included 20minute before-listening and post-listening tasks without receiving explicit extra strategy instruction as subjects in EG did.

Following a 20-minute before-listening stage using website material as the background knowledge, the EG completed 50 minutes of strategy instruction (a total of 13 weeks' instruction across the study) including the presentation, practice and review of strategies appropriate to the given listening task, which was then followed by a 30minute post-listening task.

Table 2 summarizes the course for each group (due to the space limits of the table, the non-listening activities unrelated to this study are not shown). 
TABLE 2:

COURSE OVERVIEW FOR EG AND CG

\begin{tabular}{|c|c|c|}
\hline $\begin{array}{c}\text { Groups } \\
\text { schedules }\end{array}$ & Experimental group (EG) & Control group (CG) \\
\hline Week 1 & $\begin{array}{l}\text { 30-m before-listening task } \\
40-\mathrm{m} \text { before-test } \\
20-\mathrm{m} \text { post-listening task } \\
\text { and before-questionnaires }\end{array}$ & $\begin{array}{l}30-\mathrm{m} \text { before-listening task } \\
40-\mathrm{m} \text { before-test } \\
20-\mathrm{m} \text { post-listening tasks }\end{array}$ \\
\hline Week 2-14 & $\begin{array}{l}\text { 20-m before-listening task } \\
50 \text {-m listening tasks } \\
\text { with strategies instruction } \\
20 \text {-m post-listening task }\end{array}$ & $\begin{array}{l}20-\mathrm{m} \text { before-listening tasks } \\
50-\mathrm{m} \text { listening tasks } \\
20 \text {-minute post-listening tasks }\end{array}$ \\
\hline Week 15 & $\begin{array}{l}\text { 30-m before-listening task } \\
\text { (a summary of the strategies) } \\
40-\mathrm{m} \text { post-test } \\
20 \text {-m post-listening tasks and post- } \\
\text { questionnaires }\end{array}$ & $\begin{array}{l}30-\mathrm{m} \text { before-listening task } \\
40-\mathrm{m} \text { post-test } \\
20 \text {-m post-listening task }\end{array}$ \\
\hline
\end{tabular}

\section{The Constructivism SBI in News Broadcast Listening}

Knowles once reminds us that "education is helping individuals to develop the attitudes that a lifelong process and to acquire the skills of self-directed learning" (Williams\& Burden, 2000). As a teacher, one of the most important functions is to enable the learners to become self-directed in learning activities (Wenden \&Rubin, qtd. in Williams \& Burden 2000: 147). And the strategy training of the learners can be a very important aspect to enable learners to become self-directed. Anne Brown argues that skills and strategies are best taught in relation to specific curriculum subject areas (Anne Brown, qtd. in Williams \& Burden, 2000). And the aim of this thesis is to improve students' ability in the course of news broadcast listening by implementing strategy-based instruction.

\section{Strategies to Be Instructed}

Altogether 5 kinds of sub-strategies were instructed in the research. Three meta-cognitive strategy (planning); one cognitive (prediction) and three social-affective (self-motivation, cooperation, writing news listening diary) strategies for instruction were determined, and appropriate activities were developed.

\section{The Design of Strategy Training}

In the design of this training class, 5 kinds of strategies were chosen to be instructed, which belonged to three kinds. The experimental class received the explicit strategies instruction referred above in each lesson. The treatments were divided into three periods based on the categories of the strategies instructed (as explained).

The research lasted for 15 weeks with two 45-minute classes each week. Approximately 20-30 minutes each time were devoted to the explicit news listening strategy training. Each unit was designed to include exercises and activities recommended by Vandergrift (1997a) for listening comprehension strategy training programs.

Three tasks were included in each unit. The first before-listening tasks aimed to activate students' background knowledge, and carry out the class discussion which informed the subjects about which strategy or strategies were being applied and why a strategy might be helpful with a certain kind of input. Additionally, the while-listening was focused so that a before-established goal for listening was made explicit. Besides, a great deal of exposure to the news broadcast was provided and activities which required students to speak or discuss about the topics which they had already heard. Finally a summary and feedback would be given on students' strategy use during post-listening period.

During the 15th week, the post-tests were administered to evaluate the effects of the strategy-based instruction on news broadcast listening. Post-questionnaires were also conducted after the post-tests.

A detailed training program of these 8 strategies was listed below.

1) Self-motivation Strategy

It was the first social-affective strategy to help the students to grasp in the research. The training objective of the selfmotivation strategy was to encourage a positive mentality towards news broadcast and strategy use. Motivation is one of the most important elements which make the learners eager to learn. Therefore, in the views of Constructivism, the motivation which encourages one person to learn a foreign language until he has achieved a level of proficiency will differ from individual to individual, and it is also subjected to social and contextual influences (Williams \&Burden, 2000). Besides, a three-stage model of motivation was proposed. That is: Reasons for doing something $\rightarrow$ Deciding to do something $\rightarrow$ Sustaining the effort, or persisting (Williams \& Burden, 2000).

From years' teaching of English minors, it is found that English minors enrolled at the author's school were with various reasons to attend the courses. Some chose just because of the pure interests of English studies. Some others chose English minor because they disliked their majors. Still some others were aware of the importance of English proficiency in future job hunting and their future plans of overseas studies. But some were only eager to get the credits of English which could be the scores of their public optional courses.

Due to the various motivations they had held in the studies, their views on the course of News Broadcast Listening were also different. From the interviews and chatting after class, it was also known that there were different things that they had cared for. Some were only concerned whether the exams would be difficult or not. Some cared whether their 
practical listening skills could be improved. Some were concerned whether it would help them prepare for the exams like TOEFL or other various examinations that they were preparing for.

To be frank, it was quite difficult to motivate students with so many different views in mind in a fixed and single effort. In teaching, the author firstly offered handouts with a clear comprehensive description for the course (Appendix $\mathrm{V})$.

Then the author described the benefits of the achieving news broadcast in the following aspects: (1)authentic; (2) informative; (3) cultural resource readily available outside of the classroom; (4) the reform of the exams of CET Band 4 and 6; (5) prospective job hunting and undertakings; (6) broadening horizons and knowledge scope; (7) developing global views and independent critical thinking skills.

The classroom discussions were mainly organized among students and direct presentation of the benefits of achieving news broadcast comprehension were also made as the supplements. Students discussed the way forward by improving their news broadcast comprehension through following the subsequent lessons and supports offered in the sheets, and they offered their expectations and suggestions for the course lastly. And the author summarized their views and offered the feedback for students' suggestions.

But for the students in the control group, the author gave them the handouts and explained to them one by one, but there was no discussion among students and direct explicit self-motivation training.

\section{2) Cooperation Strategy}

Along with the training of the self-motivation strategy for the students in EG, another social-affective strategy to be trained for them was the cooperation strategy. Constructivism education believes that language learning never happens in isolation, but in a certain social contexts. In the author' view, the ultimate purpose for most English learners in China is to communicate freely in their future daily life and work. Cooperation is highly valued and extremely important in interpersonal communication and working settings. Besides, the results of the questionnaires indicated that students used the least cooperation strategy in their news listening. Therefore, the objective of the cooperation strategy training was to encourage students' sharing and checking understanding, and pooling information.

Several classroom-based activities were devised to train the students' cooperation strategy. The students were divided into several groups, primarily based on their majors and genders. Some activities were carried out in groups, such as guessing games similar to some TV programs, group works to discuss a topic related to the materials to be heard. And they were expected to prepare for the PowerPoint after class, and members in the groups took different roles in the presentation, and then they were invited to present their work to others. The performance would be graded based on groups. Some groups were really well-prepared for their group works, and they did excellent and creative presentation in class.

The specific training of their cooperation strategy in while-listening was done in the class. And this was also based on their group works and the news listening tasks. A comparatively successful practice was to let students as groups prepare for the latest news reports as the extensive listening materials and then they elected the representative to present them in class teaching. One advantage of the practice was their choices of the topics and materials were the ones that they were interested in, such as the entertainment news broadcast, especially with girl members in some groups. Meanwhile, due to their language proficiency and lack of teaching practice, some of their instructions were not fully attended to by some others.

In line with the concept of whole person education in foreign language teaching, what deserves to be emphasized here was that the repeated training of the cooperation strategy with several different forms was implemented every week until the end of the course for the students in the EG.

\section{3) Strategy of Writing News Listening Diary}

Writing the listening diary, an important item of social-affective strategy, is a self-reflection of what the students have achieved in news broadcast listening. Unfortunately, from the before-questionnaires, it is clearly know that most students do not develop and apply this strategy in their listening practice as well as other skill training. Writing news listening diaries was not only a kind of strategy which students need to develop in news broadcast listening course, but a useful skill that will help them in other language learning courses. So the training of this sub-strategy was carried out through the whole term along with other strategy training. In teaching, students were required to write a brief listening diary (Appendix V) after class. For the experimental group, students were supposed to write reflective diaries, which were mainly composed of four parts:

(1) Summary of the listening practice for what they have achieved and what they have not achieved;

(2) the instructed listening strategies in class;

(3) Reflection on the learned strategies;

(4) Some suggestions to improvement in future learning and instructions.

The purpose of doing so was to make students reflect what kind of strategies they had learned in class; what kind of strategies they had applied in listening; which strategies they found most effective in solving the problems they had found in their listening process; and their attitudes, feelings and suggestions towards that class. Consequently, the students themselves can see the relationship between strategies used and how well they had completed the listening task. In this way, the diary can encourage them to reflect and evaluate their own strategy use in order to further improve their 
consciousness of the listening strategies. As far as the control group was concerned, they were also required to keep a diary after each class. But unlike the experimental group, they were asked to write down:

(1) What they had practiced;

(2) The news items that they had learned;

(3) How they managed to finish the news listening tasks in classes;

(4) What they had achieved;

(5) Plans for future listening practice.

Besides, some students were invited to share and discuss their listening diaries with classmates. In order to motivate students, their listening diaries would be considered in the final scores.

\section{4) Planning Strategy}

Planning strategy was another important item of meta-cognitive strategies that foreign language learners frequently develop and apply in learning. Although it was important for listening comprehension, it was found that the subjects in the research use this strategy infrequently from the questionnaires and the interviews.

The objective of the training planning strategy was to raise students' awareness of typical content and regularity of the discourse pattern of news broadcast in order to be clear in mind about:

(1) The knowledge that they have grasped and that can be used to facilitate news listening;

(2) What they want to comprehend: the gist, the important details, or the opinions from the guests in the broadcast, or the news terminology in the items.

(3) What they should pay special attention to or what should be noted down.

In training the planning strategy, Students in EG were required to:

(1) have discussions on how to make the plans and implement the plans in news listening, which include the purpose, the procedures and the important parts in news broadcast listening, was carried out before listening practice;

(2) to present their opinions about the strategy use.

In teaching practice, the training of every strategy was combined with certain news listening tasks. So was the planning strategy. The steps next introduce how to deal with a specific news listening tasks.

(1) Listen to several pieces of 2-3 minute VOA special English news broadcast once in full;

(2) Indicate on a worksheet if they hear the following components: News reporter overview, interviews or important details, and reporter summary;

(3) The students were invited to report whether they had caught all the components listed above and meet the plans they had made.

(4) Then some students were invited to retell the news items based on the following questions, that is: When did the incident take place? What had happened? Where did the incident happen? Who were involved? How was the incident going? Why did this happen?

(5) Then the feedback and remarks were given to the students' presentation and more listening materials were offered.

Meta-cognitive strategy is considered to be the strategy of the strategy by Oxford (Oxford 1990: 260). Planning strategy, as a kind of meat-cognitive strategy, is rather general and abstract in form, but its significance can never be ignored in helping students improve their news broadcast listening skill as well as other language skills. Hence, similar to the other strategy training, the training procedures of planning strategy were also combined with other strategies in specific tasks.

\section{5) Prediction Strategy}

According to Richards (2000), the ability to generate plausible expectations of the discourse based on the genre enhances comprehension. Yet many foreign language or second language learners neglect this strategy, perhaps due to a tendency to rely on some bottom -up strategies to comprehend the discourse.

Constructivism views on education emphasize learning through experiencing in the process. And in this learning process, the teacher is taking the role of mediator. Williams and Burden (2000: 38) propose several questions for teachers to teach learners to ask themselves the fundamental questions involved in mediation: What do you want to achieve? Do I know exactly what am I doing or what I will do next? Why am I doing it? These questions will stimulate the learners' self-motivation and lead them to make predictions.

In the author's view, a clear aim on what the learner wants to hear is the first important task before undertaking the listening practice. That is just what a learner wants to achieve before listening. In listening practice, the only thing that a learner can do before coming to the materials is to make a prediction for the aim of the listening, the key points that his selective attention should be paid to, and the contents that will be offered next in the materials.

Therefore, the training of the prediction strategy becomes especially important in facilitating students learning before and in the process. In the course of news broadcast, the authors' objective of training prediction strategy was to help students make predictions on the main ideas and important details of the news items based on all possible clues that they can grasp, and then to encourage relating of contextual knowledge to new information. The training of prediction strategy was a key part in the author's strategy training class, which was also based on the tasks of the news broadcast that the students had undertaken, or the topics that the author provided to students. 
In the before-listening activities, the author encouraged students to generate predictions on world knowledge, and to teach students the recognition of signals which were identified with certain genres. What is more, students were instructed by using the following items:

- Getting the mind ready to hear new material and link it to what we already know;

- Predicting from title, picture, and short audio clip;

- Making use of visual cues;

- The new words and news items offered ahead;

As for a specific item of news listening, the author would repeat the materials three times. After the prediction based on any possible clues, listening for the first time served to testify and relate new information to their predictions. Then the author invited some students to share what they had heard. For the twice listening, students complemented and modified their predictions through listening, and then students reported their listening and attempted to identify links between the new information and contextual knowledge to achieve partial understanding and create a more complete comprehension.

\section{E. Data Analysis and Discussion}

In this part, based on the qualitative research, the author analyzed the results of the before-interviews and the postinterviews. The author found that the students' views on news broadcast listening and strategy use in listening practice had improved positively.

\section{Results of the Interview after SBI (Strategy-based Instruction)}

In the interviews after the strategy training, another 5 students in EG were randomly selected to attend another 30minute interviews about their listening and strategy training in class. The questions were as follows:

(1) What kinds of strategies have you learned so far?

(2) Talk about your attitudes to the listening strategies, for example, whether they are useful or not.

(3) Apart from the strategies taught, do you think it necessary to learn other listening related strategies, why?

(4) Can listening strategy training help to improve your listening performance, if so, in what area?

(5) Do you have any suggestions about the teacher's strategy training?

From the interview, almost all the students agree that news report is the excellent listening materials which could greatly challenge and stimulate them to improve their listening skills after passing the examination of CET-4 \& 6 .

Besides, the interviewees talked about their views about the news listening strategy and strategy training.

Student A: Before listening to the news broadcast, I could make a conscious prediction for the main idea for the news item to be heard based on every possible clue I could catch; and I have also learned to use much more listening strategies consciously. Additionally, I will keep on writing my listening diaries, which has helped me to summarize the achievements that I have made and the problems that I need to solve.

Student B: Now I can always make an evaluation for my listening strategies to find out the existing problems and solutions. I have developed the consciousness of using listening strategies while I am doing listening practice on my own. And the training of motivation strategy has helped me to better understand my English studies, and I will use news broadcast to improve my listening skills and broaden my horizons.

Student C: I always have a clear purpose in my mind while listening, and always try to listen selectively. And I also reflect on my listening process to recall the strategies used, and to evaluate whether they are helpful or not. When I am listening, I try to associate the news with the background knowledge that I have ever read, and then I try to modify my predictions through listening.

Student D: When I finish the listening task each time, I always summarize the main idea of the news listening material and then group the words and expressions. And I have also learned to compile a word-list of news listening by myself.

Student E: I would cooperate and discuss with my friends and share my opinions with them when I met with problems and difficulties in my listening process. And now I am trying to do this in almost every course that I take.

Through the feedback received from the students, the following conclusions can be reached:

Foremost, students' consciousness of listening strategy use, especially the meta-cognitive strategies, is greatly strengthened. They can make the conscious advanced preparation and evaluation. The students have learned how to plan, monitor and evaluate their learning process better.

Then, students have already learned to cooperate with their classmates in solving the problems they encounter in news listening practice. This phenomenon demonstrates the effectiveness of the social strategy training.

Lastly, students' confidence and motivation in news listening has been increased dramatically. More students take a positive attitude toward the listening strategy training in the news listening curriculum.

Although those 5 students randomly chosen from the EG could not fully represent all the 45 students in the EG, but what they had expressed could limitedly support that the strategy-based instruction of listening to news broadcast had really improved their self-confidence and participation in news listening class. In SBI class, they had made much progress in news listening skills and developed an active and effective way of learning other skills more than listening.

\section{Comparisons and Analysis of the Data after SBI}

Similar to the before-test, the post-test were also composed of four items, such as the multiple choices, true or false, compound dictation and questions and answers. Compared with the before-test, the post-test would be a little more 
difficult in terms of topics and speed of the news broadcast, because the subjects in both groups had been practicing listening to the more diverse and challenging news broadcast for half a year. The audio materials were chosen from VOA special English, BBC Learning English and CRI reports about China.

The author carried out the comparison of independent samples t-test of the scores in post-test after SBI on news broadcast listening for subjects in EG. The independent-samples t-test indicated that the students' news listening proficiency had improved greatly. And students in EG had made a greater progress in the post-tests of news listening.

\section{3. t-test on the before-test and Post-test of Both Groups}

In order to compare the scores of the two groups in the before-test and post-test, the author conducted independentsamples T-test on the before-test and post-test of both the control group and the experimental group. As what is shown in the table 3:

TABLE 3:

INDEPENDENT-SAMPLES T-TEST ON THE BEFORE-TEST AND POST-TEST OF THE CONTROL GROUP

\begin{tabular}{|l|l|l|l|l|l|l|l|}
\hline Group & Items & $\mathrm{N}$ & Mean & SD & SEM & $\mathrm{t}$ & Sig(two-tailed) \\
\hline \multirow{2}{*}{ CG } & before-test & 43 & 71.9302 & 9.13235 & 1.39267 & \multirow{2}{*}{-2.725} & \multirow{2}{*}{0.008} \\
\cline { 2 - 7 } & Post-test & 43 & 76.9535 & 7.91910 & 1.20765 & & \\
\hline
\end{tabular}

As reflected in the table of the independent-samples t-test on the scores of the CG, for the students in CG, the mean of the post-test had also increased from 71.93 to 76.95. It was found that there was also a significant change on the mean in the control group after comparing the scores of the before-test with that of the post-test. $\mathrm{P}=0.008$, which indicates that the significance for the scores of $\mathrm{CG}$ was within the limit of 0.05 , and there was also a great significance between the scores of before-test and post-test for the students in CG. Although the students in CG did not receive explicit strategy training, they had also made progress in their news listening.

However, as reflected in the data analysis, the general improvements that students in CG had made were not as great as that of the students in EG. Table 4 shows the statistical results of the EG.

TABLE 4:

INDEPENDENT-SAMPLES T-TEST ON THE BEFORE-TEST \& POST-TEST OF THE EXPERIMENTAL GROUP

\begin{tabular}{|l|l|l|l|l|l|l|l|}
\hline \multirow{2}{*}{ Group } & Items & $\mathrm{N}$ & Mean & SD & SEM & T & Sig(two-tailed) \\
\hline \multirow{2}{*}{ EG } & before-test & 45 & 71.29 & 9.21368 & 1.37349 & \multirow{2}{*}{0} \\
\cline { 2 - 8 } & Post-test & 45 & 79.38 & 6.04637 & 0.90134 & \multirow{2}{*}{0.000} \\
\hline
\end{tabular}

For students in EG, the mean in the post-test has increased from 71.29 to 79.38. And the Standard Deviation has decreased from 9.21to 6.05, which indicated that a general improvement among all students in EG had been achieved. And the $\mathrm{P}=0.00$, which had demonstrated that a significant difference did exist between the scores of before-tests and post-tests for students in EG.

\section{4. $t$-test on the Post-test of the Two Groups}

In order to check the effects of the strategy-based instruction, another t-test was also used to make the comparison of the scores between the two groups after the 15-week strategy-based instruction of the news listening. The results are listed in the following table.

TABLE 5:

INDEPENDENT-SAMPLES T-TEST ON THE POST-TEST

\begin{tabular}{|l|l|l|l|l|l|l|l|}
\hline Item & Group & $\mathrm{N}$ & Mean & SD & SEM & \multicolumn{1}{|c|}{$t$} & Sig(two-tailed) \\
\hline \multirow{2}{*}{ Post-test } & CG & 43 & 76.9535 & 7.91910 & 1.20765 & \multirow{2}{*}{0} & \multirow{2}{*}{0.109} \\
\cline { 2 - 7 } & EG & 45 & 79.3778 & 6.04637 & 0.90134 & & \\
\hline
\end{tabular}

As is shown in the table, $\mathrm{T}=-1.619, \mathrm{P}=0.109>0.05$. From the analysis, the following aspects were found:

At first, in the post-listening test, the mean of the scores of EG was almost 3 points higher than that of the scores of CG. The average score of students in EG has improved more than their counterparts in CG. But the increase of the mean of their post-test indicated that students in both groups had made improvements in their scores of the post-test.

On the other hand, $\mathrm{P}=0.109>0.05$, which indicated that there was some significant difference for the scores of both groups to some extent. But the results of the post-test were not convincing enough to draw the conclusion that the strategy-based instruction of news listening that the author had used in teaching were superior to the traditional one and had a positive effect on the listening proficiency of the experimental group.

However, educators believe that learning is a complicated process which could be influenced by many factors, such as their motivation, instruction, and the context where learning takes place, the learning styles and teachers' teaching styles, the efforts and time that students have ever invested. And correspondingly, the results of a certain examination 
would also be affected by many factors, such as their original language proficiency, their psychological anxiety and stress, and the familiarity of the items, etc.

Another possible factor which may influence the results of the test was the use of the paper in the exams. Although previously, as the pilot test, the paper had been used for 25 sophomores of English majors, its validity and reliability had been demonstrated in their scores and their response to the papers, there was no pilot test for students of English minors. And these 25 sophomores of English majors could not represent all the other 88 English minors.

Besides, it was partly reasonable that students in CG had made progress in the post-test. In teaching, it was found that many students in CG were interested in the tasks and materials that the author had provided. They tried hard to understand more. And because there was no explicit strategy training, the time that they would use in practice was abundant, and they were also asked to listen more by themselves.

But from the other data, the author could conservatively draw the conclusion that improvement has already been made for the subjects in the experimental group.

Students in CG had also made improvements without receiving any explicit strategy training, while there was a more comparatively significant improvement in the experimental group. Thus it was conservatively concluded that the strategy-based instruction of news listening may have a positive effect on the students' listening comprehension ability.

The results had also demonstrated the doubts of some researchers as well as teachers and students on the effectiveness of strategy training in listening instruction. Yet, the results of the post-questionnaires on the other hand had proved the effectiveness of the author's 15-week strategy-based instruction of news broadcast English. More details would be given in the section next.

\section{Results of the Post-questionnaire}

After a 15-week strategy-based instruction of news broadcast listening, a comparison of the mean between EG and $\mathrm{CG}$ had indicated the effectiveness of incorporating strategies into the regular curricular syllabus.

From the interviews and communication with students, it was found that an introduction and some effective training of certain listening strategies in teaching were what many students had expected besides the repeated listening practice. And a method that would guide them to practice autonomously was also what they had expected. Therefore, similar to the training of students' pronunciation practice, listening strategy training could be another part for listening instruction, and possibly a new trend to develop the listening course and satisfy students' needs for skills and methods to learn autonomously after class.

And in order to further prove whether the strategy training incorporated into the news listening class can have a positive effect on the students' listening performance. The same questionnaires with different sequences were given to the students of both groups to see whether they had developed their views on the strategy use. And the results of the post-questionnaires were also collected and analyzed statistically. Besides, the sub-strategies that students in EG had employed in listening were also collected and compared with the ten least often used sub-strategies in the beforequestionnaires for all subjects.

Another two independent-samples T-test were conducted to compare the results of the questionnaires before and after strategy-based instruction of both groups. The results are listed in the following table:

TABLE 6:

\begin{tabular}{|c|c|c|c|c|c|c|}
\hline \multirow{7}{*}{$\mathrm{CG}$} & \multirow{7}{*}{$\mathrm{N}=43$} & \multirow{2}{*}{ Strategy } & \multicolumn{2}{|c|}{ before-questionnaire } & \multicolumn{2}{|c|}{ Post-questionnaire } \\
\hline & & & Mean & SD & Mean & SD \\
\hline & & Memory & 2.58 & 0.71 & 2.56 & 0.59 \\
\hline & & Compensation & 3.45 & 0.66 & 3.34 & 0.53 \\
\hline & & Cognitive & 3.04 & 0.48 & 3.12 & 0.43 \\
\hline & & Meta-cognitive & 3.01 & 0.40 & 2.97 & 0.46 \\
\hline & & Social-Affective & 2.42 & 0.63 & 2.38 & 0.56 \\
\hline
\end{tabular}

TABLE 7:

COMPARISON BETWEEN THE BEFORE-QUESTIONNAIRE AND POST-QUESTIONNAIRE OF EG

\begin{tabular}{|l|l|l|l|l|l|l|}
\hline \multirow{4}{*}{} & \multirow{4}{*}{ Strategy } & \multicolumn{2}{l}{ before-questionnaire } & \multicolumn{2}{l|}{ Post-questionnaire } \\
\cline { 3 - 6 } & & Mean & SD & Mean & SD \\
\cline { 3 - 7 } & Memory & 2.67 & 0.81 & 2.79 & 0.48 \\
\cline { 3 - 7 } & \multirow{4}{*}{$\mathrm{N}=45$} & Compensation & 3.36 & 0.59 & 3.42 & 0.40 \\
\cline { 3 - 7 } & Cognitive & 2.99 & 0.59 & 3.25 & 0.28 \\
\cline { 3 - 7 } & Meta-cognitive & 2.94 & 0.57 & 3.28 & 0.33 \\
\cline { 3 - 7 } & Social-Affective & 2.50 & 0.63 & 3.12 & 0.46 \\
\hline
\end{tabular}

From the table, it is clearly stated that through the strategy-based instruction, the students in the experimental class do make some progress in their strategy use and their strategy consciousness compared with the control class. Because students in EG did not receive the explicit training of some listening strategies, correspondingly, their strategy use in listening to news changed slightly compared with the previous results. But their scores in the post-tests were also increased with a comparatively smaller degree. The difference in the degrees of their improvements could not necessarily be explained as their failures of strategy use. There could be other elements which may affect the results of the post-tests. 


\section{CONCLUSION}

Through the systematic introduction and practice of 9 listening strategies in detail, students in EG got better insight into the news comprehension process and how it had worked. Results of the study have partly confirmed that a systematic explicit instruction in language learning strategies could be another way-out to develop students' news broadcast listening skills. In the research, although students in both groups had made progress in their scores of news listening tests, the minors in the experimental group had performed better than their counterparts in the control group. Besides, the model of instruction provided for teaching and applying each one of the 5 listening strategies included in the suggested training program have helped students to know why, when, and how to use the strategies they had mastered.

\section{ACKNOWLEDGEMENTS}

The research in this paper was supported by the Teaching Reform Project of Tianjin Polytechnic University: "A study on the ESP Curriculum System of College English at TJPU under the Background of 'Double First-class' Construction —-Taking Textile Engineering as an example". (NO. 2017-3-31)

\section{REFERENCES}

[1] Annie Brown. (1998). Language, Lectures, and Learning: A language-based Approach to Increasing Understanding. Education, 118: 384-393.

[2] Chen Xi. (2014). The Application of English News in College English Teaching. The Press, 10:25-28.

[3] Cheng Jingyan. (2009). The Present Situation and Future Trends of English Listening Practice. Foreign language world, 30:5156.

[4] Cui Linghua. (2006). Network VOA Resources and News listening Teaching. Computer-Assisted Foreign Language Education, 28:38-43.

[5] Dun Guangang. (2002). Listening and Teaching of Online English News. Media in Foreign Language Instruction, 36:32-37.

[6] Guan, Y. (2014). The Effects of Explicit Listening Strategy Instruction on the Listening Comprehension of English as Second Language (ESL) Community College Students. University of San Francisco, doctoral dissertation.

[7] Guo Qingzhu. (2010). English News Broadcasting. Tianjin:Nan Kai University Press.

[8] Han Shaojie \& Zhou Kexin. (2006). Research on the Design and Application of English News listening Network Teaching system. Computer-Assisted Foreign Language Education.28:47-52.

[9] He Ling. (2005). Scheme Constraints to the English News Listening. Journal of Xi'an International Studies University, 137: 65-69.

[10] Jeremy Cross. (2009). Effects of Listening Strategy on News Video-text Comprehension. Language Teaching Research, 98: 89-102.

[11] Marion Williams \& Robert Burden. (2000). Psychology for Language Teachers: a Social Constructivism Approach. London: Cambridge University Press.

[12] Oxford, R. L. \& Nyikos, M. (1989). Variables Affecting Choice of Language Learning Strategies by University Students. Modern Language Journal, 73: 291-300.

[13] Rubin (Eds.). (2004). A Guide for the Teaching of Second Language Listening. Carlsbad, CA: Dominie Press.

[14] Richards, J. C \& Nunan, D. (2000). Second Language Teacher Education. Beijing: Foreign Language Teaching and Research Press /Cambridge University Press.

[15] Teng Haicheng. (2003). Teaching EFL Listening Strategies to College Students in Taiwan. Foreign Language Learning Annals, 8: 385-394.

[16] Vandergrift, L. (1997a). The Comprehension Strategies of Second Language (French). Foreign Language Annals, 30 : 86-103.

[17] Wenden, A. \& Rubin. (1991). Learner Strategies for Learner Autonomy. NJ: Prentice Hall.

[18] Wang Lu. (2011). Exploration of English News listening Teaching. Journal of Xi'an Foreign Studies University.163:67-69.

[19] Wenjie. (2012). A case study of college English news listening. Journal of Southwest University for Nationalities (S). S1:75-79.

[20] Xia Riguang. (2004). Background knowledge Association and discourse Construction in English News listening. Media in Foreign Language Instruction, 72: 37-43.

Jinzhu Zhang, Male, lecturer at School of Foreign Languages of Tianjin Polytechnic University, Tianjin, China. His research interest lies in the Applied Linguistics and Language Testing Theory \& Practice. 